\title{
UNIVERSOS CERCANOS. EXTRANJERAS, DE HELENA TABERNA
}

\author{
Natalia Contreras
}

Universidad de Alicante

En 2008, Helena Taberna se convirtió en la primera mujer en realizar una película sobre la Guerra Civil, y lo hizo abordando una cuestión inédita en el cine español: el papel desempeñado por la Iglesia en los inicios de la guerra. La Buena Nueva ha cruzado desde entonces muchas fronteras, pero eso no nos hace olvidarnos de los inicios valientes de esta directora que no tuvo miedo de debutar con un film so-

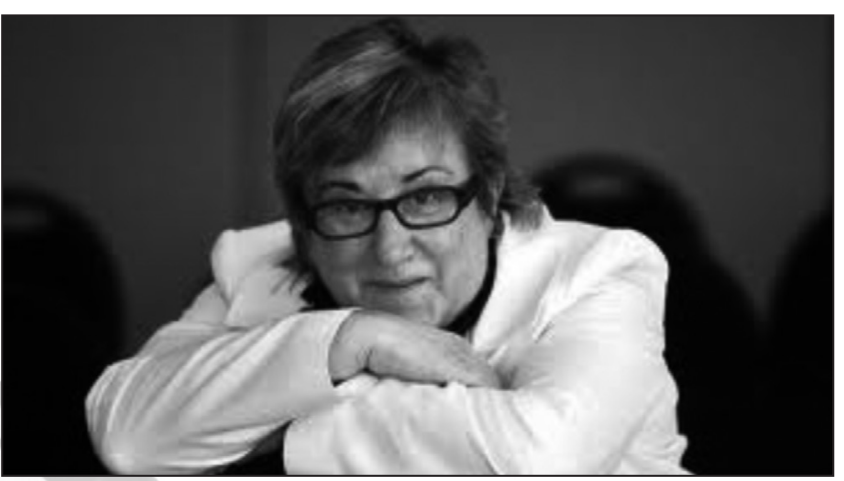
bre el terrorismo, Yoyes, y que decidió seguir su carrera con un género, el documental, con el que se siente especialmente cómoda- y a través del cual va a estrenar en la Seminci de

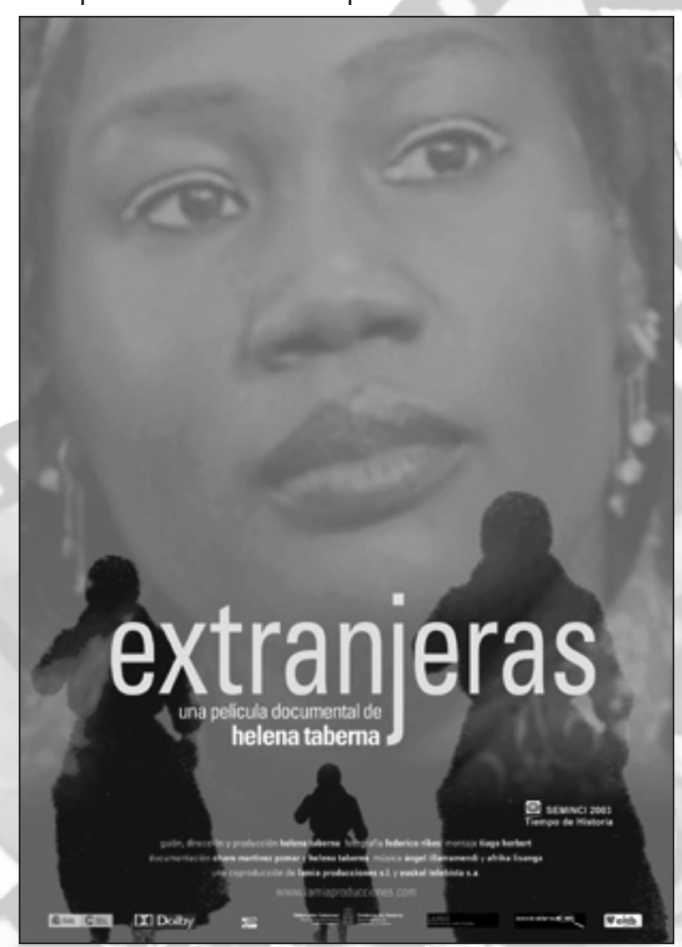

Valladolid 2010 un trabajo Ilamado Nagore basado en el asesinato de la joven Nagore Laffage.

Su segundo trabajo, el documental Extranjeras, es una mirada afectuosa sobre la experiencia vital y el itinerario emocional de un gran número de mujeres inmigrantes en el Madrid del 2003. Desde Bangladesh hasta Rumanía, la autora nos conduce por un mosaico de universos que de repente se nos hacen cercanos y, como afirma la propia directora, genera un "efecto de espejos múltiple" desde el que podemos reconocernos con otros ojos entrando en sus casas, sus cocinas, en familias, sus colegios... En esta entrevista, Helena Taberna nos explica su visión del cine como herramienta de concienciación social, de las películas como "abrazo" en los tiempos que corren y de la querencia de su cine por las cuestiones sociales en una industria como la española. 
¿En qué medida consideras que el cine -y en especial el cine documental- puede contribuir a la concienciación social y al acercamiento emocional con los hombres y mujeres inmigrantes?

Creo que mucho, porque me parece que la gran virtud del cine, y espero que esto se vaya entendiendo en el futuro -como ya se ha entendido en Francia, que ha incorporado el cine en los aspectos educativos y culturales- es provocar acercamiento emocional, sobre todo el buen cine (no vale cualquier documental), que cumpla unos requisitos de calidad, de forma que pueda incorporarse como una herramienta que el alumnado utilice. Así que yo creo que es muy interesante, que hace bien y que puede provocar transformaciones.

Tras el estreno de tu película: ¿Ha habido alguna reacción que te haya sorprendido especialmente, tanto de público como de crítica? ¿Has advertido reacciones positivas o negativas hacia ella?

Me ha sorprendido la difusión y la larguísima vida de la película. Es una película pequeñita, que surge como un brote de necesidad, de entender una sociedad que está cambiando y yo veo que mi filmografía se va construyendo desde los temas que a mí me interesan como ciudadana, de modo que yo aporto -desde lo mejor que sé hacer, que es cine- una mirada narrativa a esos hechos. La verdad es que fue recibida muy bien (ya sabes que el cine en España está muy mal en las salas y en especial el documental, que es un género que no tiene la misma aceptación en España como en otros países). Su vida en las salas no tuvo repercusión, ni mucho menos (salió con 8 ó 10 copias), pero después ha tenido mucha vida, tanto en televisiones como tras el trabajo que hicimos con ella ${ }^{1}$ en colectivos de inmigrantes, en asociaciones... ¡Y a día de hoy aún no sé qué tiene Extranjeras, que es una película que gusta a todo el mundo en todo el mundo! Me esforcé en ofrecer una mirada simpática, curiosa y con ganas de conocerles, y creo que provoca emociones muy distintas: desde la risa, a la ternura... Creo que por ahí va su secreto. Y la verdad es que se ha proyectado en los lugares más inverosímiles y seguimos teniendo pedidos desde la productora de tres o cuatro al mes.

Mujeres de Polonia, Bangladesh, Argelia, Ucrania, Marruecos, China, Siria, África, Irak, Rumanía... Después de entrevistarlas a todas, ¿te pareció que había algo que las unía más allá de sus diferencias culturales?

Sí, fue un descubrimiento, que por eso es bueno hacer cine, por todo lo que aprendes e investigas y luego lo transmites. Yo tenía la intuición de que los seres humanos somos muy parecidos aquí y allá... A mí me dijeron que había sido muy valiente por haber hecho una primera película como Yoyes -valiente desde el punto de vista temático y artístico, porque hacer eso no era fácil-.Y después del éxito de Yoyes me encontraba en Madrid y me cruzaba con estas mujeres y me decía: "bueno, estas sí son valientes y no yo": Mujeres que vienen a otro país del que desconocen la cultura, sin los recursos culturales necesarios para defenderse, sin saber la lengua... Y tuve curiosidad por saber cómo eran esas valientes anónimas. Como venía de una temática tan potente como cineasta [Yoyes], traté de mantener ese reto y mantener un relato sólido a través de lo aparentemente menos atractivo; además, sin abordar a las mujeres más poderosas o a las más visibles, que son las prostitutas. En estas, tuve especial interés en que sólo apareciera el porcentaje máximo de las que vienen aquí, por eso

1 Se ha publicado a través de su productora Lamia Producciones una guía didáctica. 
evité ese mínimo porcentaje, que siendo el menos importante es el que más atención recibe de los medios de comunicación, lamentablemente.

Tú has afirmado que tras las entrevistas que realizas para el documental "se crea un efecto de espejos múltiple en donde ellas nos muestran cómo nos ven a nosotras...". ¿Hizo este documental que la visión de tu propia cultura o de tu propia sociedad cambiara? ¿En qué aspectos?

Creo que eso nos ha pasado a todas las que la hemos visto. Allá donde se ha proyectado, Extranjeras invita al abrazo. Y creo que a nosotros nos hace falta ese punto de humildad que no siempre tenemos. Nos hicimos nuevos ricos y actuamos un poco como tal, y verla supone rescatar del olvido nuestra vida de emigrantes en el pasado, recordar que también tuvimos que ir a otros países que nos acogieron y a los que acudimos para levantarnos. Y eso es muy emocionante, y para mí lo sigue siendo cuando aún hay gente que te llama o te escribe tras la película, porque trasciende el hecho cinematográfico y te convierte en una pieza de movimiento social, incluso de reciclaje social.

Por desgracia, hoy está más de actualidad que nunca el tema de la inmigración, después de las medidas tomadas por Francia sobre los gitanos rumanos. ¿Cómo sería tu documental si lo hicieras hoy? ¿Qué cambiaría, en tu opinión?

Creo que sería menos luminoso. Lamentablemente las cosas no han ido a mejor. Yo considero que sí he hecho algo, ya que las personas que han visto Extranjeras tienen una actitud menos racista y se obligan a reflexionar sobre ello, pero por desgracia las situaciones de crisis sacan las pasiones menos buenas del ser humano, y eso está contribuyendo a que haya más barreras y más diferencias, y a que se mire al otro con más desconfianza. Y eso es muy peligroso, como estamos viendo en Francia.

Has sido la primera mujer que ha dirigido una película sobre la Guerra Civil (La Buena Nueva), has entrado de lleno en el terrorismo vasco con Yoyes y ahora estás a punto de estrenar Nagore, sobre el caso de violencia de género que acabó con la vida de la joven Nagore Laffage: ¿Ha sido una elección personal el hecho de entrar de lleno en argumentos tan "espinosos" socialmente o ha ido surgiendo en tu propia trayectoria? ¿Y qué consecuencias te ha supuesto personal y profesionalmente?

Pues la verdad es que ha ido surgiendo. Yo no tenía en cada momento esa sensación, pero así, al pasar el tiempo veo que en realidad coincide con mi curiosidad vital. Y también por pertenecer a la industria del cine español. Suelo decir que como es tan difícil hacer una película en España, prefiero hacer un "doble", es decir, que sea una película y a la vez que tenga un contexto social, de forma que eso me va a permitir que la película no sólo tenga la dimensión cinematográfica sino también de análisis temático. Y yo disfruto mientras estoy aprendiendo en la fase de documentación de todos esos temas. Creo que si consigues hacer una buena película con un contexto histórico y social, desde luego es mucho mejor. Lo que ocurre es que es más difícil, porque te arriesgas a unos panfletos que no hay ser humano capaz de soportarlos. Por eso a mí me llena de gozo que la mayor parte de las críticas no digan que hago un cine político, sino un cine poético. Me gusta que sea el espectador el que termine de construir el discurso. Es decir, me gusta que haya tantas Extranjeras como espectadores, tantas Buenas Nuevas como espectadoras... de modo que las películas no las cierro, sino que se quedan ahí, moviéndose en el corazón de la gente. 